\title{
Building on Mobile towards Better Stuttering Awareness to Improve Speech Therapy
}

\author{
Rui Neves Madeira ${ }^{1}$, Patrícia Macedo ${ }^{1}$, Pedro Pita ${ }^{1}$, Íris Bonança ${ }^{2}$, Helena Germano ${ }^{2}$ \\ ${ }^{1}$ Escola Superior de Tecnologia de Setúbal and ${ }^{2}$ Escola Superior de Saúde, Instituto Politécnico de Setúbal \\ Campus do IPS - Estefanilha, Setúbal, Portugal \\ +351265790000 \\ \{rui.madeira, patricia.macedo\}@estsetubal.jps.pt; pedropita9@hotmail.com; \{iris.bonanca, \\ helena.germano\}@ess.ips.pt
}

\begin{abstract}
This paper describes the project I Aware my Stuttering, which is a system with a focus on a mobile application for smartphones directed to people who stutter. This software will allow users to register their stuttering related situations, registering, for example, the contexts in which they occur, the interlocutors and their reactions to the situations, and the emotions felt. The application provides a reporting module that includes charts to help visualizing how stuttering situations evolve according to several features. It will help promote daily self-monitoring of speech as a means of controlling stuttering, being personalized according to the user profile. The system also offers a module for the speech therapist, which can monitor and receive reports related to users which are her/his patients. This collected data will improve the therapeutic process by enhancing discussion about registers performed immediately after a real context situation. Additionally, this paper presents a first user study conducted to assess and validate the project's purpose and the central module for registration of stuttering related situations.
\end{abstract}

\section{Categories and Subject Descriptors}

H.5.m [Information Interfaces and presentation (e.g.,HCI)]: Miscellaneous. K.m [Personal Computing]: Miscellaneous.

\section{General Terms}

Design, Experimentation, Human Factors.

\section{Keywords}

Mobile HCI, stuttering awareness, mobile computing, emotions interface, speech therapy, m-health.

\section{INTRODUCTION}

Stuttering refers to a set of disruptions in speech in which the person who stutter (PWS) knows exactly what s/he wants to speak, but at that time s/he is not able to say it due dysfluencies like blocks, repetitions or prolongations of sounds, syllables or words. Usually, stuttering is a developmental speech disorder in which the forward flow of speech is interrupted by repetitions of sounds, words, and/or the prolongation of sounds [1]. Moreover, a

Permission to make digital or hard copies of all or part of this work for personal or classroom use is granted without fee provided that copies are not made or distributed for profit or commercial advantage and that copies bear this notice and the full citation on the first page. To copy otherwise, or republish, to post on servers or to redistribute to lists, requires prior specific permission and/or a fee.

MoMM2013, 2-4 December, 2013, Vienna, Austria.

Copyright 2013 ACM 978-1-4503-2106-8/13/12...\$15.00 stuttering occurrence may be followed by facial or body movements. These changes are not due to voluntary or learned behavior [2]. PWS usually are aware of the problem and worry about it, which leads to changes in the emotional state, ranging from excitement, or tension, to even more negative emotions such as fear, embarrassment, or frustration. However, an individual does not have to be diagnosed with stuttering just to feel the fear of speaking, which is often cited as the world's most common social phobia. Its episodes can happen, now and then, to anyone depending on the context and the importance of the situation. The fear of social situations and interpersonal interaction leads to public speaking anxiety [3] and, therefore, to experience speech dysfluencies, similar to stuttering like dysfluencies but different from a stuttering condition. When the individual is unable to communicate clearly, it has an impact in every area of her/his life, speaking as little as possible because s/he is feeling embarrassed.

Motivated by the aforementioned, the project I (am) Aware (of) my Stuttering (iAmS) grew out of a partnership between the College of Technology and the College of Health Care, at the Polytechnic University of Setúbal. The project's goal arose from the need that PWS have in being aware of their problems and progress throughout their treatments. It also arose from the fact that SLPs present some difficulties in identifying in which contexts and life events occur particular stuttering situations (SS) of their patients, which would allow them to improve their intervention. Moreover, there are not efficient tools that allow SLPs to analyze SS recorded immediately after a real context situation. This lack of real context data about SS hampers the therapeutic process. Taking these fundamental needs into account, it was established that iAmS would take advantage of the ubiquity of personal mobile devices.

Nowadays, mobile devices (e.g., smartphones, tablets) are essential tools for our daily living, being almost universally connectable and appearing in almost all locations. The world has been rapidly and pervasively embracing new technologies, so it is inevitable that the healthcare area with the corresponding delivery of healthcare services would follow this scenario [4].

Given this, iAmS project is building a solution on mobile devices towards better stuttering awareness in order to improve speech therapy. The mobile application (app) under development will allow users to self-monitor their stuttering related general condition, being able to realize how they are evolving throughout treatment. iAmS is further described in the following Section. Section 3 presents preliminary results obtained with a first user study. Related work is described in Section 4 and we present conclusions and address further work in the last Section. 


\section{I AWARE MY STUTTERING}

The adoption of new technologies, particularly mobile devices, has changed the way healthcare professionals are now engaging in their daily work. The use of mobile devices in speech therapy is a fairly new direction, but speech therapists know its value, being already involved in the process of developing apps for use in this area (this work is a good example of that). SLPs familiar with mobile devices can strengthen ties with their patients and extend treatment more thoroughly into daily lives, especially with the use of apps, such as iAmS. Based on our preliminary study (see Section 3), we believe that this is a very promising way to motivate patients, get them excited about speech exercising, and support their progress. A solution like iAmS teaches patients to continually track, reflect on, and share their progress with the SLP towards learning goals. Our solution will complement the SLPs' services in helping make progress towards a more fluent speech, positive feelings/emotions related to speech, and reducing the usual speech avoidance behaviors. The app will allow users to self-monitor their stuttering related general condition, being able to realize how they are evolving throughout the treatment, in case there is one. Furthermore, it will help therapists to quickly identify, almost in real time if needed, daily life stuttering situations of users they are monitoring.

\subsection{System Overview}

The system consists of two main components: the server, which manages all the requests from the diverse apps (clients) and a central database; and the mobile application as a client (see Figure 1). The iAmS server is based on MySQL as central repository and PHP for synchronization with the apps. A first app prototype is almost fully implemented in Java for the Android platform, taking into account the prospective market penetration. Market analysts envision the continuity of a wide spreading for Android-based devices. It is not required to be connected to the Internet to use the app, but it will request periodically connections in order to do synchronizations with the server. It connects to the server to obtain and store the necessary data and this is true for all users.

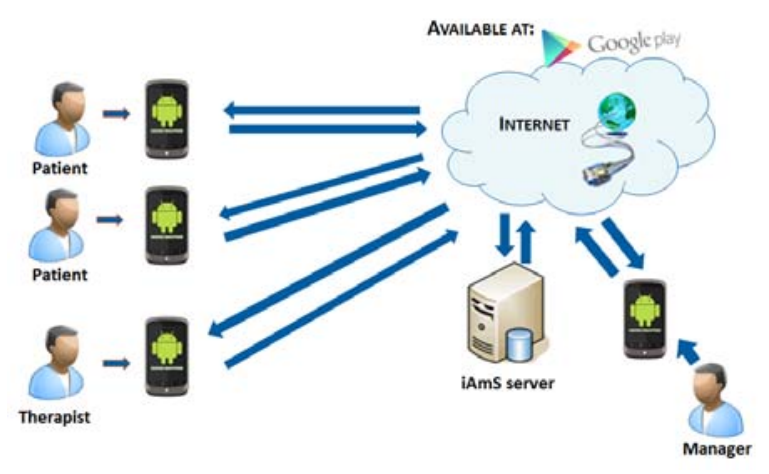

Figure 1. System's architecture.

\subsection{Rationale and Main Requirements}

This system, although being available to the general public through a GooglePlay download, is aimed primarily to users with stuttering who are or have been engaged in speech therapy, either individually or in groups. However, it is prepared to be used by anyone, even the ones without diagnosed fluency disorders, which usually feels the fear of speaking, at least, in some situations/contexts. The second most important actor to the system is the therapist, who will always be dependent on the use of iAms by her/his patients, having access only to her/his patients' data. Finally, the manager of the system is responsible, for example, for validating users, for consolidating data and managing all the aspects (e.g., emotions, reactions) that characterize a SS. This administrative module will permit the issue of a general study report for statistical and research purposes.

The iAmS app will have two different interfaces for stutterers (youth and adults), but right now it has a general one that is used to study which differences must be taken into account. As a first main goal, our research team, led by a SLP, wants the app to work as a diary. So, the user interface should be simple, clean and intuitive in order that the patient wants to use it every time s/he experiences a SS.

When using the app, first, the user has to register and create the profile in order to start recording new cases of stuttering. This requirement permits that: a patient can be associated to a SLP; the same mobile device can be used by several patients; and a user can login using different devices. Therefore, a user that is a patient has the option to introduce (or associate) the SLP that will monitor her/him throughout the use of iAmS. The therapist will have to confirm the association, after receiving a notification related to that. After being associated with users, the SLP will have access to a module in which s/he can monitor her/his patients, seeing reports with charts in the app or receiving textual reports and notifications related to the priority cases. Besides the SLP view, this reporting module has another view for the patient. The patient is able to visualize her/his evolution, being shown charts related to mood, emotions felt associated to stuttering cases, relationship between the context and intensity of stuttering, among others. These charts should always be supplemented by comments from the SLP, which should have a positive and motivating outlook indicating exercises that can be done. This should appear as a regular report.

\subsection{The Mobile Application Design}

As a first design step, content diagrams and mental models were created to debate and analyze the features needed in the interface and to establish the link between screens. Figure 2 shows a first general diagram made by the SLP team, mostly for adding a SS.

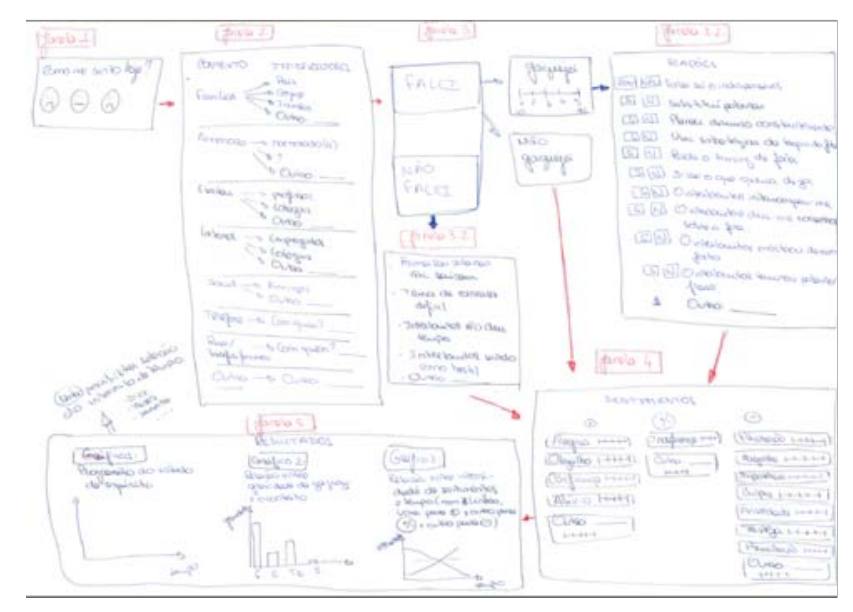

Figure 2. Initial general diagram made by the SLP team.

In the low-fidelity prototyping phase, first sketches and wireframes were drawn also to discuss the arrangement of objects 
within each screen (Figure 3), always supervised by the SLP team.

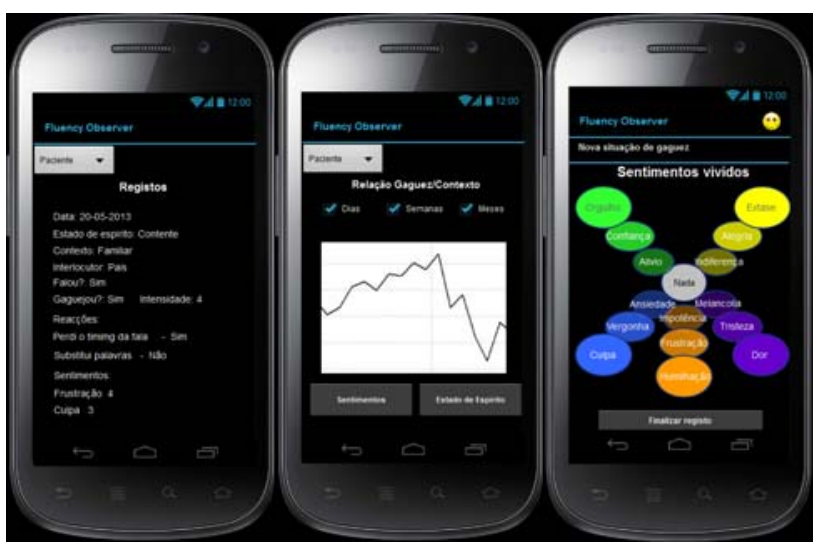

Figure 3. Initial screens design [text in Portuguese] (left and middle) SLP's screens showing a patient's SS report and a chart; (right) patient's screen to add emotions s/he felt.

The app allows the patient to change her/his mood at any moment. The action bar shows the current mood, which can be clicked on if the user wants to change it (left User Interface (UI) in Figure 4). Therefore, it will be possible to know how mood varies along the day, week, month, etc., and how it is correlated with any SS.

At this stage, the most important module to describe is the registration of an SS. It is already full functional, having been tested by a group of end-users chosen to participate in all testing phases of the whole project. Users can insert their stuttering related situations when they want, preferably soon after they happen. When added, the new situation will be associated to the current mood. The process of registering a new SS presents a well-defined flow of actions in order to select its attributes (Figure 2). This aspect is innovative in that similar apps permit the user to select which attributes to insert, but not requiring a pre-established order, which can make her/him feel somewhat lost. In our case, we found out that
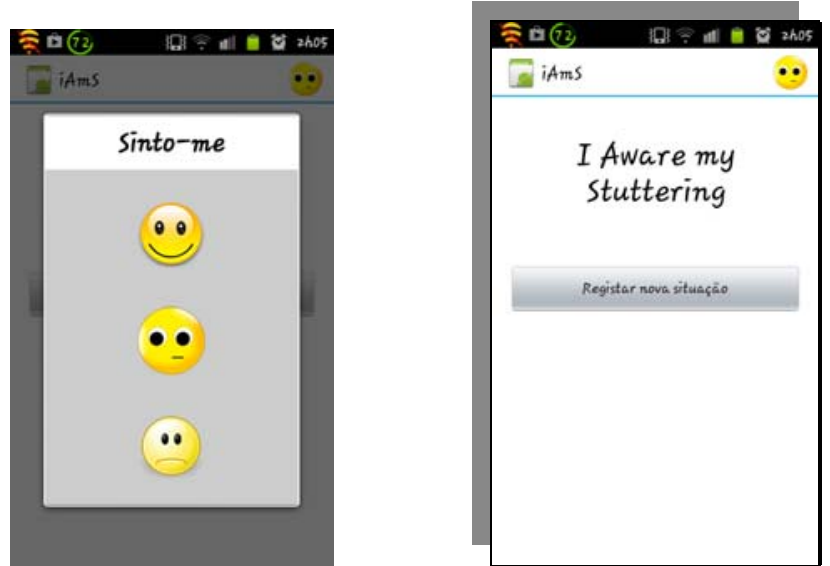

Figure 4. UI examples [text in Portuguese]: (left) mood selection; (right) start of adding an SS.

In iAmS, the process starts (Figure 4, right) with a screen to select the 1) context (Figure 5, left) in which the SS happened. It continues with the selection of the 2) interlocutors in another screen similar to the previous one. Then the user has to choose between 3) a) having spoken and b) not spoken. If s/he has spoken then $\mathrm{s} /$ he has to choose between i) having stuttered and ii) the opposite. In case of being the latter $\mathrm{s} / \mathrm{he}$ is done. If $\mathrm{s} / \mathrm{he}$ has stuttered then selects its intensity and the interlocutor's reactions. Then s/he is done. Returning to 3) b) in which s/he avoided speaking, then appears a list to select reasons for that. The last screen that appears presents a UI to select the emotion(s) felt (Figure 5, right) and this will happen every time at the end of the process. The emotions UI is an adaptation for mobile of the Circumplex Affect Assessment Tool (CAAT) [5], which is based on Robert Plutchik's Psychoevolutionary Theory and Circumplex Model. Its works very well in a mobile platform, being pleasant to use, and allowing users to express a wide spectrum of affective experiences.
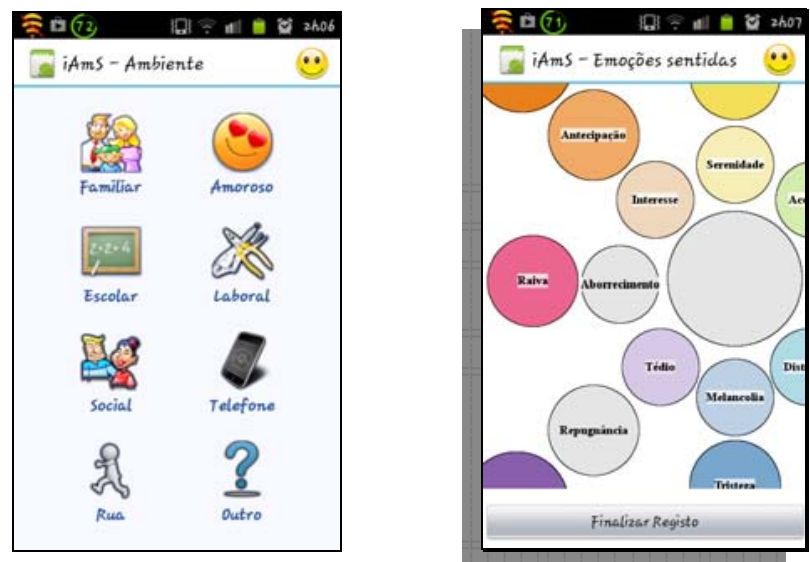

Figure 5. UI examples [text in Portuguese]: (left) context selection; (right) emotions selection.

The app should work with android 2.2 (Froyo), or later, because we intend to reach the wider range of potential users.

\section{PRELIMINARY USER STUDY}

We conducted a preliminary explorative user study with 5 participants to find out if people understand the concepts behind iAmS and imagine themselves using the app. The number of participants is considered adequate because the user audience is well defined and represented, and the evaluation scope is fairly limited. At this phase, we were only concerned with the evaluation of the task of registering a SS. Questionnaires were favored over personal interviews, although they appeared in an informal way while observing the testing process. Participants were recruited from the Institute of Expressive Therapies and the Nova University of Lisboa, with 2 females (30 and 46 years) and 3 males (ages: 13, 33, 36). For each participant, we first explained the concept and the functionalities of iAmS, besides the requested task. Finally, after having everything tested to their satisfaction, we asked the participants to fill in an anonymous questionnaire covering their speech problem background and the iAmS app with a focus on the user experience (UX) when registering a SS. We present a brief summary of our main findings.

The younger participant is the only one doing speech therapy and $60 \%$ of them never did therapy. Moreover, $60 \%$ denote that their interlocutors manifest some kind of reaction when they have stuttering episodes. Only one participant was not able to specify the beginning of the stuttering problem, because s/he suffers mostly of fear of speaking in particular stressful situations. Finally, 3 in 5 use android-based mobile devices. 
Questions related to the use of the iAmS app were of the 7-point Likert scale type. All the participants answered (between 6 and 7 points) that the process of SS registration is easy to understand, simple and straight forward and as being fast. $40 \%$ were very satisfied with the flow of actions, while $60 \%$ answered 5 points. One of them told us to change a screen and a link, which we agreed to do. All participants agreed with the use of the UI for the emotion(s) selection, being functional and integrating the emotions set usually felt. However, one participant had some doubts about the chosen set, although not specifying what was missing. Summarizing, the results are very positive showing that every user was able to accomplish the requested task in a simple and fast way. All of them reported they would like to use iAmS in the near future, considering it can be very useful.

\section{RELATED WORK}

There are some mobile-focused projects that can be used to address the stuttering problem, but none of them are distributed in our mother tongue. Interesting related examples are the following. Speech Pacer Plus [6], for iOS devices, is based on pacing and is for students/children. An example for SLPs is SLP Dysfluency Plus [6], which is an iPad app to count dysfluencies in spontaneous speech or reading samples. There are some apps for android, such as Stuttering Help [7], which provides techniques for people to control their speech fluency, and Stutter Rater [8], which is designed for SLPs and is a simple stutter counter. MPiStutter [9] is quite different supporting Modifying Phonation Intervals (MPI) stuttering therapy. Serious games are an important resource to motivate the younger patients to practice therapeutic exercises, and the Stammurai [10] is an example for iOS created by teens who stutter. Finally, Fluency SIS [11], for tablets, also has game elements and it was developed to be used by children, in order to do assessments of stuttering through play. However, the application that can be considered as a close competitor to our iAmS proposal is Fluency Tracker [12]. Table 1 compares the two solutions in terms of the main characteristics.

Table 1. The closest competition [legend: $(+)$ is better; $(=)$ is equal; (-) is worse; (0) not implemented].

\begin{tabular}{|c|c|c|}
\hline characteristics & Fluency Tracker & iAmS \\
\hline Self-monitoring & - & + \\
\hline Amount of information & - & + \\
\hline Integration of information & - & + \\
\hline Has Interface for adults & $=$ & $=$ \\
\hline Has Interface for young & - & + \\
\hline Has Interface for children & 0 & 0 \\
\hline Module for SLP & 0 & + \\
\hline Central repository server & 0 & + \\
\hline
\end{tabular}

The Fluency Tracker also allows self-monitoring of stuttering, but not in the same way as iAmS. It gives access to less reporting charts. It is mainly designed for adults or for parents of children who stutter, presenting only one user interface design. Users are able to track, but separately, changes in the frequency of disfluency, changes in avoidance behaviors, and feelings associated with speaking. Some of the harshest criticism that can be found about Fluency Tracker relates to the creation of only one profile, which is negative, for instance, to school-based SLPs that monitor multiple patients with the same device. Another important shortcoming is that it misses a central repository, which would help overcoming the previous profiling issue, besides allowing telemonitoring by the therapist.

\section{CONCLUSIONS}

This work will help promote daily self-monitoring of speech as a means of controlling stuttering, taking advantage of the ubiquitous mobile devices. Additionally, it will complement the SLP work, which can monitor and receive reports related to users which are her/his patients. Further work will follow in: i) designing different UIs for teens and for adults; ii) finalizing the system and adding English as a second app language; iii) personalizing the user experience; iv) testing the system in real context for a long term period, also with SLPs.

\section{REFERENCES}

[1] Blomgren, M. 2013. Behavioral treatments for children and adults who stutter: a review. Journal Psychol Res Behav Manag. 6, 9-19. Published online 2013 June 10.

[2] Leon, A.M., Castillo, R.C. 2009. Tratamiento de la tartamudez en niños: Programa de intervención para profesionales y padres. Elsevier Spain, S.A.; $1^{\mathrm{a}}$ ed., $1^{\mathrm{a}} \mathrm{imp}$. edition (May 1, 2009).

[3] Lee, J. M., Ku, J. H., Jang, D. P., Kim, D. H., Choi, Y. H., Kim, I. Y., and Kim, S. I. 2002. Virtual reality system for treatment of the fear of public speaking using image-based rendering and moving pictures. Cyberpsychology and Behavior journal, 5, 191-195.

[4] Lenovo, Intel and Qualcomm. 2012. Instructional technologist's guide to mobility advances: 4 opportunities to make and impact on higher education.

http://img.en25.com/Web/LenovoGroup/4_Opportunities_M ake Impact.pdf?elq mid=1475\&elq cid $=456900$ (Retrieved Aug 15, 2013).

[5] Cardoso, B., Romão, T., and Correia, N. 2013. CAAT: a discrete approach to emotion assessment. In CHI '13 Extended Abstracts on Human Factors in Computing Systems (CHI EA '13), DOI=10.1145/2468356.2468543.

[6] SLP Tap-Apps. 2013. Speech Pacer and SLP Dysfluency Plus. http://www.slp-tapapps.com/slp-tapapps.com_/ (Consulted Aug 15, 2013).

[7] Paul, P. 2013. Stuttering Help. play.google.com/store/apps/details?id=com.pcp.stutterhelp (Consulted Aug 15, 2013).

[8] Oates, M. 2013. Stutter Rater. play.google.com/store/apps/details?id=com.oatau.stutter (Consulted Aug 15, 2013).

[9] CasaFutura Tech. 2013. MSPiStutter. casafuturatech.com/mpistutter/ (Consulted Aug 15, 2013).

[10] Evil Twin Education. 2013. The Stammurai. itunes.apple.com/gb/app/the-stammurai/id370385015?mt=8 (Consulted Aug 15, 2013).

[11] Agius, J. 2013. Fluency SIS. itunes.apple.com/us/app/fluency-sis/id629966836?mt=8 (Consulted Aug 15, 2013). 